\title{
The Perils of Pain: Applying Primary Prevention to Combat Canada's Opioid Crisis
}

\author{
Zoe Lofft ${ }^{1}$ \\ 1 University of Western Ontario
}

\begin{abstract}
The development and promotion of the pain reliever OxyContin marks a dark chapter in modern healthcare, leaving lasting impact. Following the introduction of the drug in 1996 by Purdue Pharma, it became popularized among prescribers due to the company's unsupported assurance of its safety and efficacy. OxyContin has been highly profitable for Purdue but has resulted in dangerous health side effects, most notably chronic addiction. In addition, the increasing prevalence of opioid addiction exacerbates health and societal problems like illicit drug use, especially the abuse of other opioids like heroine and fentanyl. The ramifications of the opioid crisis extend beyond individual health problems, causing social issues, economic burden and political tensions as well. In response to this, the Canadian National Advisory Committee on Prescription Drug Misuse created the "First Do No Harm" strategy, focusing on prevention, education, treatment, monitoring and surveillance. Although these strategies have been applied with some success, opioidrelated deaths and costs continue to grow in Canada. A primary preventative approach that focuses on using epidemiological data to reduce opioid access is thought to be an important part of ongoing strategies. Primary prevention will assist in improving the health of Canadians, mitigate future opioid-related healthcare costs and ultimately contribute toward stopping their ongoing distribution. In doing so, the future Canadian healthcare landscape, families and patients alike may be spared the collateral damage opioids cause.
\end{abstract}

KEYWORDS: Opioid Crisis, Canadian Healthcare, Primary Prevention, Big Pharma Subject Area Health Sciences, Medical Sciences

\section{Introduction}

The opioid crisis is a well-known cause of health, social and economic problems in Canada. Common adverse health effects of opioid use include sedation, dizziness, respiratory depression, physical dependence and most notably, addiction (1). This is significant because 669,674 Ontarians are reported opioid users (2). The crisis originated from the introduction of an allegedly safe pill that offered promise of pain relief at no cost. Paradoxically, painkillers may be the greatest pain of all, to patients and the Canadian healthcare system alike. Instead of working symbiotically, big pharmaceutical companies are choosing marketing over morals and medicine, at the expense of patient health. Meanwhile, Canadian healthcare dollars are being left to pick up the tab. Canada's national strategy to combat this issue holds promise, but some of its applications are arguably latent and uneconomical. The prevention aspect of Canada's strategy should be highlighted as most hopeful and cost effective. Specifically, a primary preventative approach should be emphasized to minimize the perpetuation of this issue.

\section{Historical Context}

Oxycodone hydrochloride, popularly known as OxyContin, belongs to a class of extended release, long-acting oral opioids. Purdue Pharma introduced it to the market in 1996, for the treatment of pain. Initially, there was hesitation around prescribing OxyContin, so Purdue conducted research and hosted focus groups to find out why. They unveiled that doctors worried about potential abuse of the new drug (3). Consequently, they set out to strategically curb these beliefs. This was done largely through sponsorships and seminars targeted at medical students, since medical school and residency are formative years in establishing prescribing practice (4).

Between the years 1996 and 2002, Purdue funded more than 20,000 pain-related educational programs through direct sponsorship or financial grants. They also launched a multifaceted campaign to actually encourage long-term use of opioid pain relievers for chronic non-cancer pain, without knowing scientifically established, long-term side effects (3). In addition, Purdue provided free textbooks to medical students that contained false information about the safety and intensity of OxyContin. Particularly, erroneous amendments were made to a World Health Organization report, adding OxyContin to a list of weaker, safe opioids in the textbook (5). Therefore, the strategies in the promotion of the drug ignored ethical and moral 
considerations by advertising unsubstantiated claims.

\section{Current Issues}

Presently, Canada is the world's second highest user, per capita, of prescription opioids (6). In 2010, Purdue sold $\$ 250$ million worth of OxyContin in Canada and by 2015, doctors wrote one opioid prescription for every two Canadians (5). Meanwhile, in 2010, prescription opioids were involved in 16,651 overdose deaths and some $82 \%$ of these deaths were cited as unintentional (7). Meaning, the mortality caused by opioid use largely resulted from patients who were advised to use it and prescribed it by their doctors. In the wake of this adversity, big pharmaceutical companies, like Purdue, have dichotomized addiction and physical dependence in an attempt to escape blame. They alleged that "physical dependence" was clinically unimportant and the pejoratively stigmatized condition labeled as "addiction" was rare (3). Considerable efforts have been made on the part of pharmaceutical companies to separate prescription opioid users and nonmedical illicit opioid drug users, conveniently pegging any risks, mortality and growing healthcare costs with the latter.

However, this façade bears a feeble front. According to the National Survey on Drug Use and Health, four out of five current heroin users report that their opioid use began with opioid pain relievers (3). Often, this was because a patient would develop an addiction to the prescription opioid they were on and then experience withdrawal when the dose ran out. So, if ineligible to have the prescription refilled, street drugs were relied on. In fact, heroin was cited as less expensive and more accessible on the black market than getting prescription opioids (3). Additionally, in 2010, prescription opioid overdose deaths were five times higher than overdose deaths linked to heroin (7). Today, heroin is far from the only problem. By no coincidence, between 2009 and 2013 in Ontario, hydromorphone and fentanyl prescriptions increased by $79 \%$ and $20 \%$ respectively, as the provincial government limited OxyContin availability (8). Plainly, this suggests that the origin of the opioid epidemic and current fentanyl crisis lies in the hands of companies like Purdue.

\section{Canada's Strategy}

North American practitioners are now left in a difficult position, facing the dual challenge of chronic pain and addiction, with the line separating them highly ambiguous. Chronic pain is a serious issue that affects millions and is often associated with functional loss, disability and reduced quality of life (9). Thus, it is vital that it still be addressed with appropriate medications and treatment. Opioids at times may be appropriate, but unnecessary access to them exacerbates health and social issues. To address this, the Canadian National Advisory Committee on Prescription Drug Misuse created the "First Do No Harm" strategy. The development of the strategy is rooted in five streams: prevention, education, treatment, monitoring and surveillance (10). This collaborative approach forms a strong theoretical framework for combatting the opioid problem. Unfortunately, the present application of these strategies may be lacking.

\section{Prevention}

In an attempt to prevent illicit use, companies are working to develop abuse deterrent formulas. Acura Pharmaceuticals is one of the leading companies in this and has patented what they call "Aversion Technology". This technology aims to make it more difficult and uncomfortable to extract the active ingredient from opioid pills and use them intravenously or through the nasal passage (11). For example, when mixed with a solvent the pill will turn into a gel and when ingested through the nasal passage it will cause increased burning and irritation (11). This proposed preventative measure might be more designed for manufacturers to maintain sales than to confront the opioid crisis. Research from the University of Toronto suggests that tamper-resistant formulas may only be effective in deterring individuals who intend to manipulate a medication (8). Apart from that, they have not been effective in preventing addiction or death (8). Overall, this strategy fails to recognize that many illicit users begin as prescribed users and ultimately, it enables the continuation of opioid access and distribution.

\section{Education}

In response to the opioid crisis, the Food and Drug Administration (FDA) released a position paper highlighting that much of the problem is due to illicit use. Accordingly, their proposed solution entails training opportunities and education sessions for doctors (12). The sessions are funded through opioid product manufacturers, which could be a conflict of interest because companies are unlikely to recommend their products be discontinued, due to 
their financial interest. A similar emphasis on prescriber education is promoted in Canada. This is largely done through the Canadian Medical Protective Association (CMPA), which also advocates for educating prescribers about "red flag" patients, who may be compulsive opioid-seekers (13).

Although the educational strategies put forth by the FDA and CMPA may be valuable in theory, they currently lack a targeted approach. Namely, they do not address that some doctors may be disproportionally accountable for opioid access by overprescribing. This is a vital consideration because resources are finite and should be tailored to populations where they will be most impactful.

\section{Treatment}

The most widespread treatment for prescription opioid dependence in Ontario is methadone maintenance treatment (MMT). Ontario has about 50,000 patients currently enrolled in MMT, which is three to four times higher than the rate of the United States (14). The high reliance on MMT is problematic because it is costly. In fact, the current annual public expenditures for MMT in Ontario are estimated to be over $\$ 250,000,000$ (14). Meanwhile, it has been estimated that Purdue has made more than $\$ 30$ billion from OxyContin sales in Canada and the United States since the mid 1990s (5).

Although MMT is effective in reducing opioid abuse, it should not be the treatment most frequently relied on for opioid dependence. It is an aggressive treatment that may be more intensive than some patients require. Research suggests that alternative treatments including detoxification therapies, behavioural counselling and even abstinence can be effective for some users (14). Using these alternatives, where possible, would spare lifelong reliance on MMT.

\section{Future Directions}

All of the previously discussed strategies have their merits and reasoning as solutions in combatting the opioid crisis. However, it was revealed that they might be inefficient economically and fail to prevent future opioid dependence and addiction. To improve this, primary prevention should be considered paramount in all of the strategies.
Primary prevention focuses on preventing new cases from developing by reducing access to opioids. An epidemiological approach is a key element of primary prevention. The Centres for Disease Control and Prevention defines epidemiology as, "the study of the distribution and determinants of health-related states or events in specified populations, and the application of this study to the control of health problems" (15). Primary preventative approaches can be integrated into existing strategies to improve their efficacy and reduce future incidence.

For example, population-based research in Ontario used prescription data and records from the Office of the Chief Coroner to track prescription patterns. It revealed that patterns in Ontario varied widely; the highest $20 \%$ of opioid-prescribing family physicians issued opioids 55 times more often compared to the $20 \%$ who prescribed them least frequently (16). The physicians' characteristics associated with increased opioid prescription were male, older in age and practicing for longer (16). Thus, education sessions should specifically target this demographic of prescribers to reduce access to opioids (16).

In addition, social marketing has been thought to be a promising primary preventative application (3). An informative public advertisement campaign could be designed to alert and educate people about the risks opioids pose. Using a mass media channel of communication is advantageous because doctors often have limited time to fully discuss all potential drug side effects with patients, unless they specifically ask. This may reduce future opioid access as patients become more critical about the drugs being prescribed to them. It may open the conversation to discussing the side effects of drugs or considering alternative treatments, based on their informed understanding.

\section{Conclusion}

The widespread damage from opioid abuse is evident. For the prevention of future damage, it will be salient to integrate primary preventative measures as part of existing strategies. This will help to ensure sustainability of the healthcare system and most importantly, the longevity of patients. Despite all the breakthroughs and merit some modern pharmaceuticals have provided, warnings by ancient Roman authors like Cato, who lived as early as 234 
BC, may offer some truth: "Beware of doctors, they would bring death by medicine" (17).

\section{References}

1. Benyamin R, Trescot AM, Datta S, Buenaventura R, Adlaka $\mathrm{R}$, Sehgal $\mathrm{N}$, et al. Opioid complications and side effects. Pain Physician. 2008; 11: 105-120.

2. Canadian Institute of Health Information $(\mathrm{CIHI})$. Substance use surveillance [Internet]. Ottawa: $\mathrm{CIHI} ; 2017$ [cited 2017 Nov 11]. 6p. Available from: https://www.cihi.ca/sites/default/files/document/sus enewsl etter_issue_2_en.pdf

3. Kolodny A, Courtwright DT, Hwang CS, Kreiner P, Eadie JL, Clark TW, Alexander GC. The prescription opioid and heroin crisis: a pubic health approach to an epidemic of addiction. Annu. Rev. Public Health. 2015; 36: 559-574.

4. Zipkin DA, Steinman MA. Interactions between pharmaceutical representatives and doctors in training. $J$ Gen Intern Med. 2005; 20(8): 777-786. doi: 10.1111/j.15251497.2005.0134x.

5. Robertson G, Howlett K. How a little-known patent sparked Canada's opioid crisis. The Globe and Mail. [Internet]. 2017 May 17 [cited 2017 May 30]; Drugs: [about 12p.]. Available from: https://www.theglobeandmail.com/news/investigations/oxyc ontin/article33448409/

6. Fischer B, Argento E. Prescription opioid related misuse, harms, diversion and interventions in Canada: a review. Pain Physician. 2012; 15(3): 191-203.

7. Volkow ND, Frieden TR, Hyde PS, Cha SS. Medicationassisted therapies- tackling the opioid-overdose epidemic. N Engl J Med. 2014; 370(22): 2063-2066. doi: 10.1056/NEJMp1402780.

8. Leece P, Orkin AM, Kahan M. Tamper-resistant drugs cannot solve the opioid crisis. CMAJ. 2015; 187(10): 717-718. doi: 10.1503/cmaj.150329.

9. Olsen Y, Sharfstein JM. Chronic pain, addiction, and Zohydro. N Engl J Med. 2014; 370(22): 2061-2063.

10. National Advisory Committee on Prescription Drug Misuse. First do no harm: Responding to Canada's prescription drug crisis. [Internet]. Ottawa: Canadian Centre on Substance Abuse; 2013 [cited 2017 Nov 11]. 81p. Available from: http://www.fgta.ca/docs/0-

First Do No Harm Responding to Canada\%E2\%80\%99 s Prescription_Drug Crisis - Canada-StrategyPrescription-Drug-Misuse-Report-en.pdf

11. Moorman-Li R, Motycka CA, Inge LD, Congdon JM, Hobson S, Pokropski B. A review of abuse-deterrent opioids for chronic nonmalignant pain. P T. 2012; 37(7): 412-418.

12. U.S. Food and Drug Administration. Attention prescribers: FDA seeks your help in curtailing the U.S. opioid epidemic [Internet]. Silver Springs: US Department of Health and Human Services; 2013 [cited 2017 May 30]. 5p. Available from:

https://www.fda.gov/Drugs/DrugSafety/InformationbyDrugCl ass/ucm330614.htm

13. Mertl S. Doctors need education on prescribing opioids CMAJ. 2016; 188(14): 1003-1003. doi: 10/1503/cmaj.1095322.

14. Fischer B, Kurdyak P, Goldner E, Tyndall M, Rehm J. Treatment of prescription opioid disorders in Canada: looking at the 'other epidemic'? Subst Abuse Treat Prev Policy. 2016; 11(1): 1-12. doi: 10.1186/s13011-016-0055-4.

15. Centres for Disease Control and Prevention. An introduction to applied epidemiology and biostatistics. [Internet]. Atlanta:
US Department of Health and Human Services; 2012 [cited 2017 June 3]. 3p. Available from: https://www.cdc.gov/ophss/csels/dsepd/ss1978/lesson1/sec tion1.htm

16. Dhalla IA, Mamdani MM, Gomes T, Juurlink DN. Clustering of opioid prescribing and opioid-related mortality among family physicians in Ontario. Can Fam Physician. 2011; 57(3): 92-96.

17. Porter R. Antiquity. In: The greatest benefit to mankind: A medical history of humanity. New York \& London: W.W. Norton \& Company; 1997. 55-81. 